\title{
Thermography with excitation by elastic waves: comparison of techniques (pulse, burst, lockin)
}

\author{
by Th. Zweschper, A. Dillenz, G. Riegert, G. Busse
}

University of Stuttgart, Institute of Polymer Testing and Polymer Science (IKP),

Department of Nondestructive Testing, Pfaffenwaldring 32, 70569 Stuttgart, Germany

\begin{abstract}
Ultrasound thermography or sonic thermography is being used for defect-selective imaging where the background of intact structures is suppressed. This concept is helpful in terms of reliability and speed of inspection. However, as compared to optical excitation the method implies high power ultrasound injection, which is a considerable load on the inspected structure. Hence one needs to consider which technique provides which information at which load. Our paper discusses these topics on the base of various examples.
\end{abstract}

\section{Introduction}

Ultrasound or sonic thermography can be used as a rapid and reliable non-destructive technique. Several excitation and evaluation techniques are compared in this paper.

Ultrasound Lockin Thermography (ULT), which was developed a few years ago [1], Ultrasound pulse thermography, and Ultrasound burst phase thermography (UBP) are compared.

All three techniques provide defect selective imaging using thermal waves generated by elastic waves. The mechanism involved is local friction or hysteresis, which turns a variably loaded defect into a heat source, which is identified by thermography even in the presence of complicated intact features [2]. In comparison to the sinusoidal excitation of the ULT method, UBP uses only short ultrasound bursts to derive phase angle images [3]. Therefore UBP combines the advantages of both lockin and pulse thermography. It allows for faster measurements with a better reproducibility while the advantages of phase images are the same: depth resolved recognition of defects, suppression of inhomogeneous emissivity and temperature gradients.

\section{Excitation methods}

\subsection{External excitation: Optical Lockin Thermography (OLT)}

OLT is derived from thermal wave techniques with detection at only one spot $[4,5,6$, 7], which where used very early to detect thermal boundaries in materials.

A low frequency thermal wave is generated on the whole surface of the inspected component and monitored everywhere several times per modulation cycle in order to obtain an image of amplitude and phase of temperature modulation [4, 8, 9] (Figure 1). The inspection time is given by a few modulation cycles. As one can image large structures (up to some square meters) within a few minutes [10], one has a powerful method for fast inspection of safety relevant structures with a depth range of several millimeters in CFRP.

Once the advantage of signal phase had been discovered, phase angle imaging became a reliable tool for imaging of hidden structures due to the enhanced depth range and its independence on optical [11] or infrared surface patterns.

However, OLT $[12,13]$ provides a map of all thermal structures, and one needs to search deviations from these known structures in order to identify defects. 


\subsection{Internal excitation: Ultrasound Lockin Thermography (ULT)}

Further investigations were performed in order to obtain a method where defects can be revealed like in a dark field method. Mechanical properties of samples with a defect can vary: The resonance frequency may be shifted, the stiffness can change, and the mechanical loss angle is increased locally. This effect is used for ULT. The local weakness, which results in a locally enhanced damping, is used to convert elastic waves into heat $[14,15]$ (Figure 2). These elastic waves are injected using a high power ultrasound converter. The amplitude of the high frequency output signal is modulated at the low lockin frequency. The lockin thermography system is tuned to this frequency and provides amplitude and phase information.

\subsection{Internal excitation: Ultrasound Burst Phase Thermography (UBP)}

Another method, which allows for significant reduction of inspection time, is the use of sonic pulses to excite the sample $[15,16]$ (Figure 3 ). The spectral components of the cooling down period after burst excitation provides information like the lockin method but much faster [17]. This evaluation technique using Wavelet or Fourier transform is being used for optical pulse excitation as well $[18,19]$. The signal to noise ratio of the phase and amplitude images is much better than for single temperature images [3]. The following example confirms that high frequencies probe only near-surface regions while low frequencies with their larger depth range provide information about defects deeper inside the component.

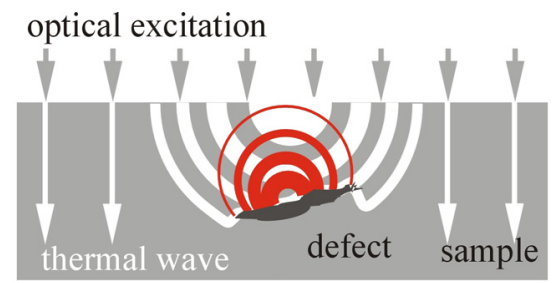

reflected thermal wave

Fig. 1. Principle of lockin thermography with optical excitation (OLT).

thermal wave

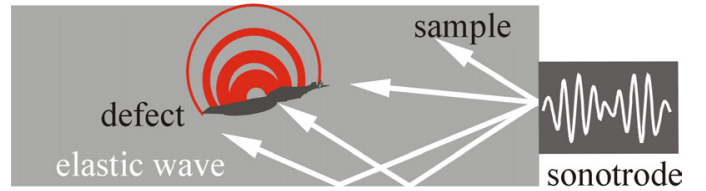

Fig. 2. Principle of lockin thermography with ultrasonic excitation (ULT).

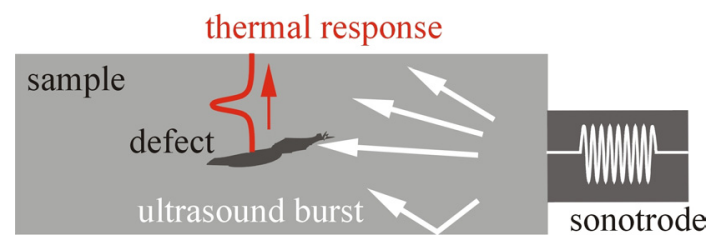

Fig. 3. Principle of ultrasound burst thermography (UBP). 


\subsection{Experimental arrangement}

A CEDIP Jade II infrared focal plane array camera was used to capture temperature sequences with a frame rate up to $130 \mathrm{~Hz}$. The $320 \times 240$ detector array is sensitive in the 3-5 $\mu \mathrm{m}$ regime. The experimental configuration for OLT uses an arbitrary signal generator, which can be controlled in real time providing the input signal for the light source. This signal is synchronized to the recording process of thermal images. Up to 12 lamps each one with an electrical input power of $1 \mathrm{~kW}$ can be used allowing for an inspection area of several $\mathrm{m}^{2}$.

The configuration for ULT or UBT includes an ultrasound transducer with a resonance frequency of $20 \mathrm{kHz}$ or $40 \mathrm{kHz}$ respectively. The bandwidth is limited by $10 \mathrm{kHz}$. The electrical input power is as high as $2 \mathrm{~kW}$.

\section{Comparison of methods and applications}

\subsection{Damage detection with OLT, ULT and UBP on the example of damaged stringer structures}

Stringers are useful to enhance the stiffness of skins along certain directions. Consequently, disbond of stringers caused by overloading results in a loss of structural stiffness. Therefore one is highly interested to detect such defects early enough to prevent failure. Ruptures of stringers in aerospace components are a serious problem because this kind of damage is almost invisible from the outer surface of an aircraft for most nondestructive testing methods, since stringers are hidden behind a panel. The access from inside the aircraft is difficult and time consuming.

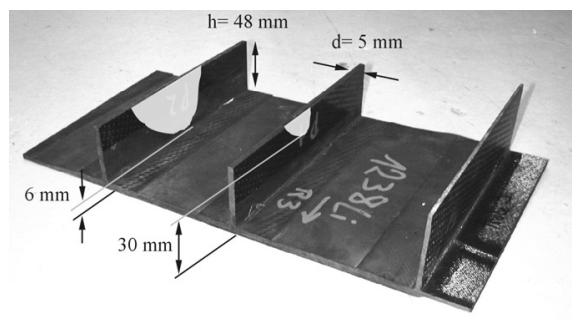

a) CFRP stringer structure. Thickness of skin: $6 \mathrm{~mm}$. Laminated stringer (thickness $5 \mathrm{~mm}$, height $48 \mathrm{~mm}$ ). Ruptures are marked white.

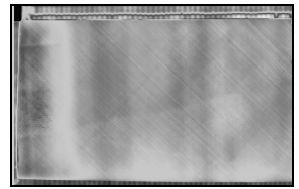

b) Optical Lockin Thermography Phase image at $0.01 \mathrm{~Hz}, 200 \mathrm{~s}$ acquisition time

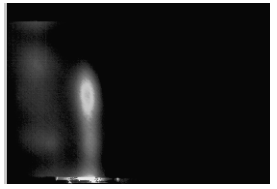

c) Ultrasound Lockin Amplitude image at $0.01 \mathrm{~Hz}, 400 \mathrm{~W}$, and $100 \mathrm{~s}$ acquisition time

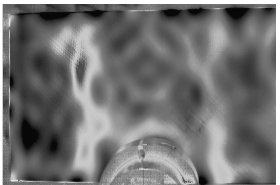

d) Ultrasound Lockin Phase image at $0.01 \mathrm{~Hz}$ $400 \mathrm{~W}$, and $100 \mathrm{~s}$ acquisition time

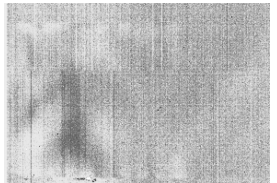

e) Ultrasound Burst Phase image at $0.0485 \mathrm{~Hz}$, burst length 5 s, $400 \mathrm{~W}$

Fig. 4. Comparison of different phase images of ruptures in an aerospace component

The CFRP structure to be inspected had ruptures in its stringers as shown schematically in Figure 4a. A CFRP skin with a thickness of more than $6 \mathrm{~mm}$ covered the damage. While stringer delaminations can be detected with Optical Lockin Thermography [10], the depth range of optically generated thermal waves is not sufficient to reveal hidden stringer ruptures (Figure $4 b$ ). Ultrasound Lockin Thermography (Figure $4 c$ and $4 d$ ) 
and Ultrasound Burst Phase image (Figure 4e) can reveal the rupture in the left stringer clearly. The signal to noise ratio, however, is much better for the ULT technique compared to UBP. The damage in the right stringer is too far from the surface $(30 \mathrm{~mm})$, therefore it remains undetected even with sonic excitation.

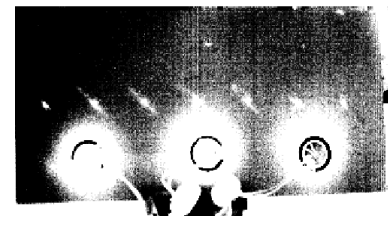

a) Temperature image one second after sound injection.

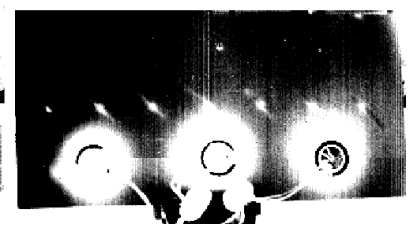

b) UBP: amplitude image at $0.24 \mathrm{~Hz}$

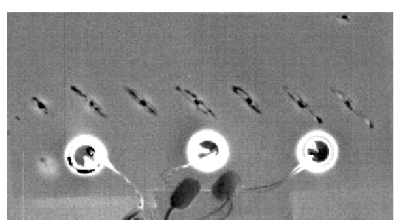

c) UBP: phase image at $0.24 \mathrm{~Hz}$

Fig. 5. UBP: amplitude and phase image of seven impacts in CFRP (d=2 $\mathrm{mm})$

\subsection{Damage detection using small piezo-ceramic actuators}

From previous investigations it is known that soft materials could be damaged by injecting elastic waves with high energy [20]. An alternative approach is the use of many small distributed piezo-ceramic actuators to generate an elastic wave field in the inspected component. This results in a reduction of mechanical and thermal load. Here we examined a thin carbon fiber plate with seven impact damages. Three piezo-ceramic actuators were bonded to the sample to generate a wave field at a frequency of $8 \mathrm{kHz}$ with $200 \mathrm{~W}$ during 1 second. Some milliseconds after the excitation burst, the best thermal contrast for defect detection is achieved (Figure 5a). However, there is only a small change in temperature at the damaged regions of the sample. The amplitude image calculated with a Fourier transform at $0.24 \mathrm{~Hz}$ is an improvement in terms of signal to noise ratio (Figure 5b). The defects are displayed with better contrast, but friction between sample and actuators still causes thermal fringes around the actuators. This effect is much reduced in the phase image derived from the same sequence (Figure $5 \mathrm{c}$ ), where inhomogeneity of temperature variations are eliminated.

\subsection{Suppression of standing waves using frequency modulation}

Ultrasound thermography measurements are often disturbed by standing waves which occur when the frequency of the sound excitation is a resonance frequency of the sample. Due to hysteretic losses, these standing elastic waves can appear as temperature patterns causing misinterpretations: In the worst case the defect could be hidden in a node ("blind spot") while the standing wave maximum might appear as a defect. This can be avoided by using two or more ultrasound converters with several frequencies simultaneously or, even better, by frequency modulation of a sinusoidal signal. In these cases the standing wave pattern is superimposed by a field of propagating waves giving sensitivity also where only nodes existed before.

As an example, a CFRP plate was excited with a frequency of $20 \mathrm{kHz}$. The temperature image is given in Figure 6 , left. The signal to noise ratio is rather poor. The situation improves by using phase evaluation on the same measurement. However, a standing wave pattern occurs, which can be eliminated by modulation the excitation frequency between $17 \mathrm{kHz}$ and $23 \mathrm{kHz}$ at a wobble frequency of $25 \mathrm{~Hz}$. As a result of nonresonant coupling, the input power had to be increased by a factor of two in order to achieve the same elastic power density inside the sample. However, the standing waves are reduced significantly. 


\section{Conclusion}

ULT, UBP and sonic pulse thermography were compared. The advantage of frequency modulation was demonstrated. One can conclude that ULT provides good results even if the inspected component is very large and thick. A drawback is the relatively high thermal and mechanical load since the inspection may take more than a minute. To avoid this, the use of short bursts should be considered (UBP) where the inspection time is reduced. As a drawback back, the signal to noise ratio is reduced as compared to the lockin technique. Both methods are to be preferred to the sonic pulse (timegram) method with its low $\mathrm{S} / \mathrm{N}$ ratio.
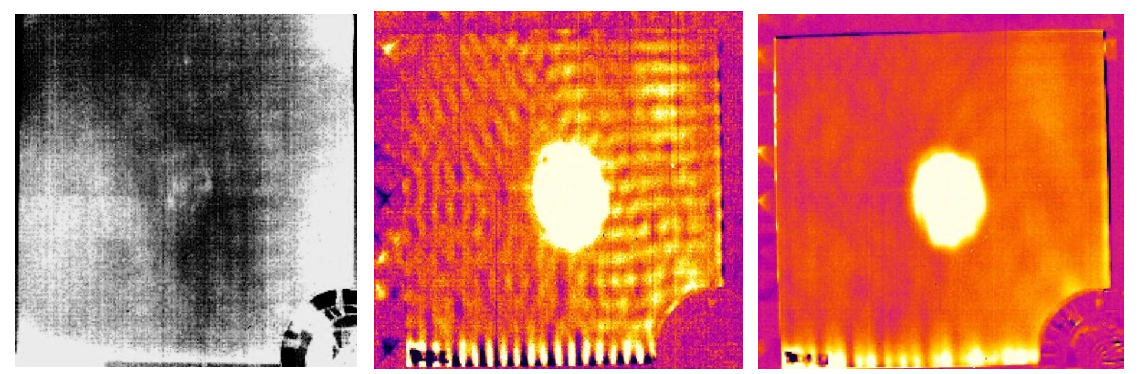

Fig. 6. left: temperature image, burst length $500 \mathrm{~ms}, 1 \mathrm{~kW}, 0,52$ seconds after burst Middle: monofrequent excitation $f_{R}=20 \mathrm{kHz}$ phase at $0.06 \mathrm{~Hz}$ burst length $500 \mathrm{~ms}, 1 \mathrm{~kW}$ Right: frequency modulated excitation $f_{\text {mod }}=25 \mathrm{~Hz}$ $f_{R}=17 \ldots .23 \mathrm{kHz}$ phase at $0.06 \mathrm{~Hz}$ burst length $500 \mathrm{~ms}, 2.2 \mathrm{~kW}$

Further reduction of thermal and mechanical load is possible if arrays of small piezoceramic actuators are used. However, this way of energy deposition allows for damage detection only in near-surface layers (CFRP: up to two or three $\mathrm{mm}$ ).

\section{Acknowledgements}

We are grateful to DLR e.V., Stuttgart and Airbus Deutschland GmbH for excellent cooperation and for providing samples.

\section{REFERENCES}

[1] RANTALA, J., WU, D., BUSSE, G., "Amplitude Modulated Lock-In Vibrothermography for NDE of Polymers and Composites". In: Research in Nondestructive Evaluation Vol. 7 (1996), pp. 215-218

[2] ZWESCHPER, TH., DILLENZ, A., BUSSE, G., "Ultrasound Lockin Thermography a NDT Method for the Inspection of Aerospace Structures". In: QIRT 2000, Lodart S.A.: Akademickie Centrum Graficzno - Marketingowe, Lodz, Poland (2001), pp. 224-229, ISBN 83-89003-45-7

[3] DILLENZ, A., ZWESCHPER, TH., BUSSE, G., "Elastic wave burst thermography for NDE of subsurface features", Insight 42 [12], 2000, pp. 815-817.

[4] BUSSE, G., "Optoacoustic phase angle measurement for probing a metal". In: Appl.Phys.Lett. Vol. 35 (1979), pp. 759-760

[5] ROSENCWAIG, A., "Photoacoustic microscopy". American Lab. 11 (1979), pp.39-49

[6] NORDAL, P.-E., KANSTAD, S.O., "Photothermal radiometry". In: Physica Scripta Vol. 20 (1979), pp. 659-662 
[7] THOMAS, R.L., POUCH, J.J., WONG, Y.H., FAVRO, L.D., KUO, P.K., ROSENCWAIG, A., "Subsurface flaw detection in metals by photacoustic microscopy". In: J.Appl.Phys. Vol. 51 (1980), pp. 1152-1156

[8] LEHTO, A., JAARINEN, J., TIUSANEN, T., JOKINEN, M., LUUKKALA, M., "Amplitude and phase in thermal wave imaging". In: Electr. Lett. Vol. 17 (1981), pp. 364-365

[9] UO, P.K., FENG, Z.J., AHMED, T., FAVRO, L.D., THOMAS, R.L., HARTIKAINEN, J., "Parallel thermal wave imaging using a vector lock-in video technique". In: Photoacoustic and Photothermal Phenomena, ed. P. Hess and J. Pelzl. Heidelberg: Springer-Verlag (1987), pp. 415-418

[10] [WU, D., SALERNO, A., MALTER, U., AOKI, R., KOCHENDÖRFER, R., KÄCHELE, P.K., WOITHE, K., PFISTER, K., BUSSE, G., "Inspection of aircraft structural components using lockin-thermgraphy". Busse, G.; Balageas, D.; Carlomagno, G.M. (Hrsg.): Quantitative infrared thermography, Stuttgart, 2-5 September, 1996. Pisa: Edizione ETS, 1997, pp. 251-256, ISBN 88-467-0089-9.

[11] ROSENCWAIG, A., BUSSE, G., "High resolution photoacoustic thermal wave microscopy", Appl. Phys. Lett. 36, 1980, pp. 725-727.

[12] CARLOMAGNO, G. M., BERARDI, P. G., "Unsteady thermotopography in nondestructive testing", Proc. 3rd Biannual Exchange, St. Louis/USA, 24.-26. August 1976, pp. 33-39.

[13] BEAUDOIN, J.L., MERIENNE, E., DANJOUX, R., EGEE, M, "Numerical system for infrared scanners and application to the subsurface control of materials by photothermal radiometry". In: Infrared Technology and Applications, SPIE Vol. 590 (1985), p. 287

[14] STÄRK, F., "Temperature measurements on cyclically loaded materials", In: Werkstofftechnik 13, Verlag Chemie GmbH, Weinheim (1982) pp. 333-338

[15] MIGNOGNA, R.B., GREEN, R. E. Jr., HENNEKE, E.G., REIFSNIDER, K.L., "Thermographic investigations of high-power ultrasonic heating in materials". In: Ultrasonics 7 (1981), pp. 159-163

[16] FAVRO, L. D., XIAOYAN HAN, ZHONG OUYANG, GANG SUN, HUA SUI, THOMAS, R. L., "Infrared imaging of defects heated by a sonic pulse", Rev. Sci. Inst. 71, 6 (2000), pp. 2418-2421.

[17] Patent DE 10059854.4

[18] MALDAGUE, X., MARINETTI, S., "Pulse Phase Infrared Thermography". In: J. Appl.Phys. 79-5 (1996), pp. 2694-2698.

[19] [19] GALMICHE, F., MALDAGUE, X., VALLERAND, S., COUTURIER, J.-P., "Pulsed Phased Thermography with the Wavelet Transform". In: QNDE, Montreal (1999), pp. 609-615

[20] BUSSE G., DILLENZ, A., ZWESCHPER, TH., "Defect-selective imaging of aerospace structures with elastic-wave-activated thermography", Thermosense, 1620. April 2001, Orlando, USA 